\title{
Soluble dietary fiber fraction of Trigonella foenum graecum seeds prevent olanzapine induced metabolic syndrome in rats
}

\begin{abstract}
Trigonella foenum graecum (TF) belongs to the family Fabaceae, it has been from ancient time, used as a spice and traditionally ethno pharmacological medicine for promoting digestion and reduce blood sugar levels in a diabetic patient in India. In the present study, soluble dietary fiber (SDF) was isolated from TF seeds and investigates the role of SDF of TF, against olanzapine induced metabolic complications. Metabolic syndrome was induced by oral administration of OLZ $5 \mathrm{mg} / \mathrm{kg}$ in rats for 28 days. Then rats were treated with OLZ and SDFF of TF at 250 and $500 \mathrm{mg} / \mathrm{kg}$; po./day and metformin as a standard $100 \mathrm{mg} / \mathrm{kg}$; po./ day. SDF of TF treatment significantly decreased body weight gain, feed and water intake, blood glucose, oral glucose tolerance test (OGTT), lipid profile, liver enzymes, uric acid and improved hemodynamic parameters, antioxidant status and reduced histopathological changes caused by OLZ treatment in rats. SDF of TF increased the satiety, suppresses appetite and improved the glucose and lipid metabolism and antioxidant potential exert the beneficial role in olanzapine induced metabolic syndrome.
\end{abstract}

Volume 2 Issue 3 - 2018

\author{
Kiran Saini, ' Ajay Singh Kushwah,' \\ Ghanshyam Das Gupta ${ }^{2}$ \\ 'Department of Pharmacology, ASBASJS Memorial College of \\ Pharmacy, India \\ ${ }^{2}$ Department of Pharmaceutics, Indo-Soviet Friendship Colleges \\ of Pharmacy, India
}

\begin{abstract}
Correspondence: Ajay Singh Kushwah, Department of Pharmacology, ASBASJS Memorial College of Pharmacy, India, Tel +91-9417459195, Email kushwah_ph05@yahoo.co.in
\end{abstract}

Received: May 17, 2018 | Published: June 05, 2018

Keywords: olanzapine, metabolic syndrome, soluble dietary fiber, trigonella foenum graecum, galactomannan

Abbreviations: MS, metabolic syndrome; AMPK, activated protein kinase; AGRP, agouti related peptide; BAT, brown adipose tissue; SDF, soluble dietary fiber

\section{Introduction}

People with severe mental illness die up to 3 decades earlier than the general population and cardiovascular diseases are responsible for more than $50 \%$ of mortality in the population with schizophrenia. ${ }^{1}$ Average life expectancy in people with schizophrenia is about 20 years shorter than the normal population. ${ }^{2}$ It is reported that cardio metabolic complications such as obesity, hypertension, dyslipidemia, insulin resistance, diabetes mellitus associated with metabolic syndrome (MS) are well-recognized side effects of antipsychotics particularly the atypical which are widely used today for schizophrenia. ${ }^{3}$ The introduction of atypical antipsychotics proves to be a significant advance in the treatment of schizophrenia as compared to older, typical antipsychotics provides some improvement in negative and cognitive symptoms, while exhibiting the marked reduction in extrapyramidal side effects. ${ }^{4}$ Cardiovascular side effects of antipsychotics may due to increase in appetite, weight gain, and hyperglycemia and lipid metabolism disturbances. Literature revealed that olanzapine leads to higher metabolic side effects than most other antipsychotics, only second to clozapine. ${ }^{5}$ The mechanisms underlying olanzapine (OLZ) induced weight gain and metabolic dysfunctions involve both central and peripheral mechanisms which converge to metabolic dysfunction. ${ }^{6}$ Initial increases in body weight are primarily caused by increases in appetite due to antagonism of multiple central receptors including 5- $\mathrm{HT} 2 \mathrm{C}$, histamine $\mathrm{H}_{1}$ and dopamine $\mathrm{D}_{2}{ }^{7}$ Weight gain and obesity associated with olanzapine are mediated by activation of the hypothalamic AMP-activated protein kinase (AMPK) pathway via blockade of the $\mathrm{H}_{1}$ receptor. ${ }^{8} \mathrm{OLZ}$, in the arcuate nuclei $(\mathrm{Arc})$ of the hypothalamus,down-regulates the anorexigenic neuropeptide proopiomelanocortin (POMC) but upregulates the orexigenic neuropeptide Y (NPY) and agouti related peptide (AGRP). Furthermore, it also reduced activation of the brown adipose tissue (BAT) is associated with obesity and diabetes in humans. ${ }^{9}$ OLZ also change the levels of hormones related to weight regulation, such as insulin and leptin which may affect the sensitivity of satiety neurons in the lateral hypothalamus. ${ }^{10}$ It increases ghrelin level which is responsible for the increase in appetite and also associated with peroxisome proliferator-activated receptors and transcriptional regulators of lipid and carbohydrates metabolism. ${ }^{11}$ Metabolic complications with atypical antipsychotics have raised concerns about a possible relation between these metabolic effects and treatment with these medications. ${ }^{12}$ Psychiatrists need to educate and motivate patients to make healthy lifestyle changes. If these lifestyle changes fail, these patients need to receive drug interventions. Adding medications such as metformin, topiramate, and amantadine or switching to another antipsychotic drug should be considered to decrease the risk of antipsychotic induced weight gain and metabolic abnormalities..$^{13}$ In the battle to prevent obesity and related problems associated with olanzapine, satiety inducing food ingredients such as dietary fiber offer a natural dietary strategy for caloric intake control and body weight regulation..$^{14}$ Dietary fiber could play an important role in the management of the metabolic complications and to positively affect those factors implicated in cardiovascular disease. ${ }^{15}$ The plant Trigonella foenum-graecum (TF) belongs to family Fabaceae is the famous spice, it is commonly known as Methi (Hindi) and Fenugreek (English). TF is known for its pleasantly bitter and slightly sweet seeds. ${ }^{16}$ It is mostly cultivated in India, parts of West Asia, Middle East, North Africa, United Kingdom, Russia, Mediterranean Europe, Australia, US and Canada. ${ }^{17}$ Traditionally and ethno pharmacological uses of TF are in various disorders as antidiabetic, antihypercholesterolemic antioxidant, hepatoprotective, gastroprotective, antinociceptive, antibacterial, anti-fungal, antiinflammatory and antineoplastic. ${ }^{18-21}$ Phytoconstituents of Trigonella foenum-graecum present in seeds such as carbohydrates, saponins, flavonoids, hemicelluloses, mucilage, tannins, 4-hydroxyl-isoleucine 
and pectin and especially fiber which is comprised of mainly $50 \%$ fiber (30\% soluble fiber and $20 \%$ insoluble fiber). ${ }^{22}$ Also, TF husk is a valuable source of soluble dietary fiber (SDF) and phenolic acids; therefore, it could be an effective source of natural antioxidants. ${ }^{23}$ Galactomannans are the main soluble fiber present in seeds and form a gelatinous structure (similar to guar gum) which may have effects on slowing the digestion and absorption of food from the intestine and create a sense of fullness in the abdomen, thus suppresses appetite and promotes weight loss. ${ }^{24,25}$ The rationale of selection of the plant revealed that presence of various phytoconstituents which are responsible for the different activities. However, there are no sufficient studies have been carried out to explore the role of soluble dietary fiber rich fraction of TF, whereas a number of studies show that extract and powder of seeds ameliorate reduction in weight, glucose and lipid profile. ${ }^{26,27}$ Therefore, thought to work on SDF of TF seeds to explore its potential to reverse the metabolic complications associated with atypical antipsychotics. In the present study aims to investigate the role of SDF of TF in the prevention of olanzapine induced metabolic syndrome in rats.

\section{Materials and methods}

\section{Plant materials and preparation soluble diateryfraction (SDF) of Trigonella foenum-graecum (TF)}

Seeds of the plant were purchased from the local market and authenticated by Dr. Sunita Garg, Head of the Raw Materials Herbarium \& Museum, Delhi (CSIR-NISCAIR) Ref. No. NISCAIR/ RHMD/Consult/2017/3088-37. Trigonella foenum graecum (TF) seeds were dried at $40^{\circ} \mathrm{C}$ and finely powdered. The powder was weighed and $10 \%$ of the dilute acetic acid solution was added; mixed thoroughly with the mechanical stirrer for four hours and centrifuged using 3000rpm for $30 \mathrm{~min}$. The supernatant solution was transferred and volume was measured, four volumes of $95 \%$ ethyl alcohol were added, mixed thoroughly and allowed to settle for one hour to get precipitation of soluble dietary fiber (SDF) fraction. It was filtered through muslin cloth and washed with $95 \%$ ethyl alcohol and the residue was collected and dried overnight in hot air oven at $60^{\circ} \mathrm{C}$ and powdered..$^{15}$ This isolated powder had $66.91 \%$ SDF enriched with galactomannan. ${ }^{28}$

\section{Drugs preparation}

Olanzapine procured from Micro Labs Ltd. Baddi (HP) India, was dissolved in normal saline and administered at the dose of $5 \mathrm{mg} / \mathrm{kg}$, po./day. Metformin was obtained as gift sample from Swaroop Drugs $\&$ Pharmaceuticals Maharashtra, India and dissolved in normal saline and administered at a dose level of $100 \mathrm{mg} / \mathrm{kg}$, po./day. All the other chemicals used were of analytical grade.

\section{Experimental animals}

The research protocol of this study had been approved by Institutional Animal Ethics Committee (IAEC) of ASBASJSM College of Pharmacy, Bela (Ropar) vide approval no. ASCB/ IAEC/08/16/109.Thirty-five albino female Wistar rats weighing 200-220g were procured from Central Animal Facility, AIIMS, New Delhi. The animals were kept in quarantine section till monitoring of health status of animals and subsequently transferred to the housing area. The animals were housed in standard size polypropylene cages using husk as bedding in the controlled conditions of temperature $\left(23 \pm 2^{\circ} \mathrm{C}\right)$, humidity $(40 \pm 10 \%)$ and $12: 12 \mathrm{~h}$ dark/light cycles. The animals were fed with standard diet and purified water was given ad labium as per CPCSEA guideline.

\section{Experimental design}

The Female Wistar rats of weight 200-220gm were divided into six experimental groups ( $\mathrm{n}=5-6 /$ group) and were matched by body weight. The following six groups were studied for 28 days Figure 1. Normal control (C) rats received only $0.1 \mathrm{ml}$ normal saline, SDF of TF parse group (TF 500) rats were received SDF $500 \mathrm{mg} / \mathrm{kg}$; po./ days, Olanzapine (OLZ) group administered $5 \mathrm{mg} / \mathrm{kg}$; po./days of olanzapine to induce metabolic syndrome and study group OLZ with two different dose of SDF of TF at dose $250 / 500 \mathrm{mg} / \mathrm{kg}$; po./ days(OLZ+TF 250) and (OLZ+TF 500) respectively; OLZ with Metformin standard group (OLZ+Metformin) $100 \mathrm{mg} / \mathrm{kg} / \mathrm{po} /$ days . The standard and treatment drugs were administered after OLZ treatment. The doses were selected on the basis of literature report. ${ }^{19,29}$ The body weight, food intake and water intake of rats were evaluated daily. Blood analysis and hemodynamic parameters evaluated after the end of the study $29^{\text {th }}$ day. After these studies, the animals were sacrificed by decapitation to estimate tissues TBARS, GSH levels, and histopathological studies were carried out.

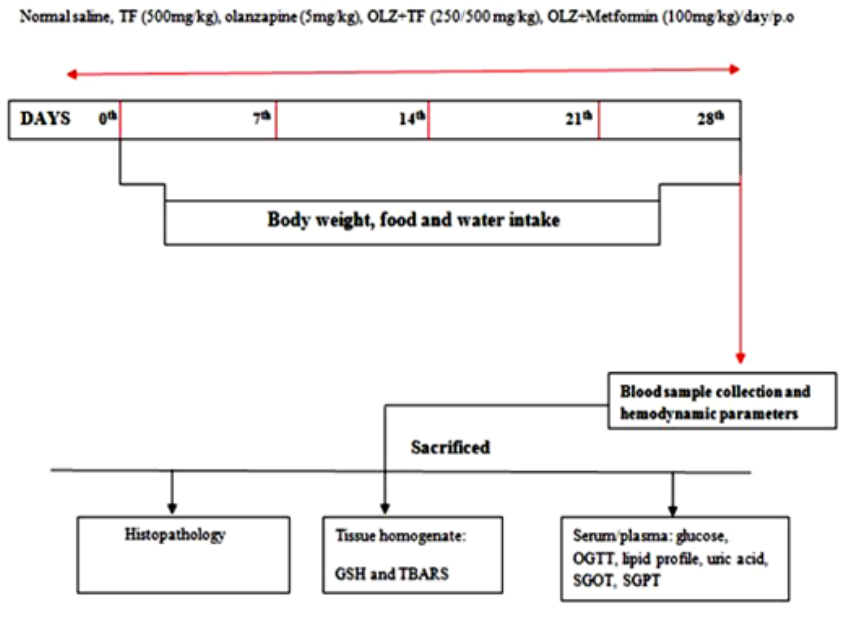

Figure I Flow diagram of experimental study protocol.

\section{Serum biochemical analysis}

The blood sample was obtained from the overnight (16h) fasted rats after the administration of the last dose (on $29^{\text {th }}$ day). The blood was collected by puncturing retro-orbital plexus using heparinized glass capillary tubes under chloroform anesthesia and collected in Eppendorf tubes and then centrifuged at $3000 \mathrm{rpm}\left(40^{\circ} \mathrm{C} 10 \mathrm{~min}\right)$ serum was separated for analysis of different haematological parameters such as Glucose, OGTT, cholesterol, HDL (high density lipoprotein), LDL (low-density lipoprotein), TG (triglycerides), SGOT and SGPT and uric acid. All analysis was performed with-commercially available kits using autoanalyzer (Reckon Diagnostics, Chandigarh and Span Diagnostics Ltd., Surat, Erba Diagnostics, Baddi). TBARS, GSH levels, and histopathological studies were carried out.

\section{Oral glucose tolerance test (OGTT)}

OGTT was performed by measuring plasma glucose at the end of the study period in each group. The rats fasted for $16 \mathrm{~h}$ and blood samples were collected by retro-orbital plexus. A dose of $2 \mathrm{~g} / \mathrm{kg}$ (body 
weight) glucose solution was given by gastric gavages. Blood samples were obtained from the retro-orbital plexus at pre and 30,60 and $120 \mathrm{~min}$. post glucose intake. Plasma glucose levels were measured by available kits using autoanalyzer (Reckon Diagnostics, Chandigarh).

\section{Measurement of hemodynamic parameters}

Rats were anesthetized with $25 \%$ urethane $(1.5 \mathrm{~g} / \mathrm{kg}$, i.p) Throughout the experimental protocol body, temp of the animals was maintained at $37^{\circ} \mathrm{C}$. The neck was opened with a ventral midline incision to perform the tracheotomy. The left carotid artery was cannulated with the Polyethylene tube (internal diameter $0.30 \mathrm{~mm}$; outer diameter $0.40 \mathrm{~mm}$ ) attached to a three-way cannula. The cannula was heparinized (Heparin 300IU/ml) and connected to POWER LAB 4/30 (AD Instruments, NSW, Australia) system using a pressure transducer for the measurement of systolic, diastolic, mean arterial pressures and heart rate.

\section{Measurement of biochemical parameters}

Animals were sacrificed by cervical dislocation and the heart tissues were removed, washed with the cold isotonic saline and dried with filter paper. After this hearts were isolated and homogenize in $0.05 \mathrm{M}$ ice cold phosphate buffer. After centrifugation, the supernatant was used for analysis of antioxidant enzymes GSH and TBARS. ${ }^{30,31}$

\section{Histopathology}

The animals were sacrificed; the liver was isolated, washed with ice cold saline and fixed in neutral buffered formalin (NBF) for not less than 6 hours. ${ }^{32}$ The samples were sent pathology department of IVY hospital, sec-71, S.A.S Nagar (Mohali) for the preparation of slides of liver tissue and stained using $\mathrm{H} \& \mathrm{E}$ staining technique. For interpretation, the pictures were taken from the prepared slides with the help of photo- microscope.

\section{Statistical analysis}

The data were expressed as Mean \pm SEM was analyzed by one-way ANOVA followed by Tukey multiple comparison tests using Graph Pad Prism software package. A value of $\mathrm{P}<0.05$ was considered to be significant.

\section{Result and discussion}

Effect of soluble diatery fraction (SDF) of Trigonella foenum-graecum (TF) on body weight, feed intake and water intake

Antipsychotic-induced metabolic disorders are the risk factors for cardiovascular disease, insulin resistance and diabetes mellitus resulting in increased morbidity and mortality. ${ }^{33}$ Weight gain has been very serious issue frequently with olanzapine and other atypical antipsychotics drugs. ${ }^{34}$ Several mechanisms of olanzapine have been postulated, including its antagonistic effect on $\mathrm{D}_{2}, 5-\mathrm{HT}_{2 \mathrm{C}}, \mathrm{H}_{1}$ and $\mathrm{M}_{3}$ receptors, some reports have correlated the weight gain with leptin and/or ghrelin, which cause hyperphagia ${ }^{34}$ Various scientific reported that olanzapine administration could induce weight gain in the female, but not male rats. ${ }^{35}$ Some natural drugs containing phenolic and flavonoids have reversal effects on metabolic complications associated with olanzapine. ${ }^{36}$ Numerous therapies found that metformin can improve weight gain and insulin resistance induced by antipsychotics and reduce metabolic syndrome or type-2 diabetes. ${ }^{37} \mathrm{It}$ is reported that effect of TF mediated by the ability of galactomannan to reduce absorption of lipids by inhibition of intestinal lipases enzyme, decreased $\mathrm{HMG}-\mathrm{CoA}$ reductase activity and increased biliary cholesterol excretions..$^{38} \mathrm{OLZ}$ is reported to increase in weight gain, feed and water intake in several clinical and animal studies. ${ }^{39}$ In study elucidated the effects of SDF of TF supplementation on OLZ $(5 \mathrm{mg} / \mathrm{kg}$, po.) induced metabolic syndrome. Body weight, feed, and water intake were compared with normal control rats; OLZ group and OLZ with TF $(250 / 500 \mathrm{mg} / \mathrm{kg})$ and metformin group, the initial body weights were not different among the groups. In study animals treated with olanzapine increased body weight, feed and water intake as compared with normal control group (Table 1) (Figure 2) (Figure 3). The body weight gain in OLZ groups was higher than in the normal control group after the $28^{\text {th }}$ day. Whereas the body weight of OLZ with SDF of TF at 250 and $500 \mathrm{mg} / \mathrm{kg}$ and OLZ with metformin group were observed to significantly decrease body weight, feed and water intake compared to the OLZ group $(\mathrm{P}<0.05)$. The high dose of TF 500 showed more significantly $(\mathrm{P}<0.05)$ results as compare to lower dose of TF 250. An increase in feed consumption indicates that OLZ causes hyperplasia and leads to weight gain in rats. ${ }^{29}$ Body weight was found to be significantly elevated, probably due to increased feeding. Some studies show that increased feed efficiency and insulin resistance and activated hypothalamic AMPK are also might be involved in OLZ induced weight gain. ${ }^{40}$ It has been proposed that olanzapine leads to an alteration in adipocytokines such as leptin which regulate the body weight by an effect on food intake, energy consumption and glycolipid metabolism. ${ }^{41}$

Table I Effect of soluble diateryfraction (SDF) of trigonella foenum-graecum (TF) on average weight gain and average percentage change of body weight

\begin{tabular}{lll}
\hline Groups & $\begin{array}{l}\text { Average weight } \\
\text { gain }\end{array}$ & $\begin{array}{l}\text { Percentage } \\
\text { change }\end{array}$ \\
\hline Normal control & $25 \pm 2.069$ & $115 \pm 1.372$ \\
TF $(500 \mathrm{mg} / \mathrm{kg})$ & $17.58 \pm 2.227$ & $110.0 \pm 1.377$ \\
OLZ control $(5 \mathrm{mg} / \mathrm{kg})$ & $90.8 \pm 1.782^{\mathrm{a}}$ & $154.0 \pm 1.428^{\mathrm{a}}$ \\
OLZ+TF $(250 \mathrm{mg} / \mathrm{kg})$ & $81.4 \pm 2,42^{\mathrm{b}}$ & $149.0 \pm 2.035^{\mathrm{b}}$ \\
OLZ+TF $(500 \mathrm{mg} / \mathrm{kg})$ & $56.07 \pm 1.556^{\mathrm{b}, \mathrm{c}}$ & $132.8 \pm 1.074^{\mathrm{b}, \mathrm{c}}$ \\
$\begin{array}{l}\text { OLZ+Metformin } \\
(100 \mathrm{mg} / \mathrm{kg})\end{array}$ & $48 \pm 1.572^{\mathrm{b}}$ & $128.2 \pm 0.888 \mathrm{I}^{\mathrm{b}}$ \\
\hline
\end{tabular}

The total duration of the study was 28 days.

Values are expressed as Mean $\pm \operatorname{SEM}(n=5-6) .{ }^{a}(p<0.05)$ vs normal control group;

${ }^{b}(p<0.05)$ vs olanzapine control group; ${ }^{c}(p<0.05)$ vs low dose TF $(250 \mathrm{mg} / \mathrm{kg})$ treatment group

(One way ANOVA followed by Tukey's test)

\section{Effect of soluble diateryfraction (SDF) of trigonella foenum-graecum (TF) on serum biochemical parameters}

It has been reported also that $\mathrm{TF}$ acts by delaying glucose absorption and enhancing its utilization and hypoglycemic effect of $\mathrm{TF}$ are due to phytoconstituents mainly galactomannan present in seeds which help in the management of metabolic abnormalities associated with diabetes such as peripheral insulin resistance and lipid abnormalities. ${ }^{38}$ Anti platelet activity PPAR $\gamma$ agonists and HMG-CoA reductase inhibitors like constituents in this plant exerts beneficial effects on several physiologic markers relevant to metabolic syndrome. Olanzapine increased the liver fat and enzymes 
thus promote the intrahepatocellular lipids and cause endothelial dysfunction. ${ }^{42}$ TF fiber has been shown to inhibit glucose absorption and decrease postprandial hyperglycemia and these effects were attributed to delay gastric emptying of carbohydrate, inhibition of intestinal lipase and increased gut motility. It has been proposed that TF seeds exert hypoglycemic effects by stimulating glucose dependent insulin secretion from pancreatic beta cells. In the present experiment, the continuous treatment for 28days with the TF showed a potential anti hyperglycemic effect and OGTT activity when compared to OLZ treated rats. Studies show that OLZ induced glucose and insulin dysregulation may be partly due to blockade of muscarinic $M_{3}$ receptors, causing disruption to insulin secretion and glucose homeostasis that can progressively lead to insulin resistance and diabetes during chronic treatment. ${ }^{43}$ The ability to modify glucose homeostasis perhaps due to the presence of $\beta$-glucan and fiber fraction increased both insulin-stimulation and basal glucose uptake by AMPK activation as reported in previous. ${ }^{44}$ Long-term consumption of olanzapine produces a lipoprotein profile, associated with the development of the cardiovascular disorder and metabolic syndrome. Elevated plasma concentrations of total cholesterol (TC), low-density lipoprotein (LDL) cholesterol and reduced high-density lipoprotein (HDL) are commonly seen in dyslipidemia. The administration of olanzapine results in excess hepatic lipids accumulation due to increased synthesis and decreased secretion of lipids and increased lipogenesis. ${ }^{45}$ OLZ group in the plasma biochemical analysis glucose, cholesterol, triglycerides (TG), LDL, SGOT, SGPT and uric acid levels increase significantly $(\mathrm{P}<0.05)$ were as significantly lower HDL level as comparing the normal $(\mathrm{P}<0.05)$. Effects of TF (SDF) on the biochemical parameters of glucose and lipid levels in the OLZ+TF 250 and OLZ+TF 500 group had significantly $(\mathrm{P}<0.05)$ reduced cholesterol, TG, and LDL levels, whereas HDL levels in OLZ with TF groups increased when compared to the OLZ group. In OLZ+ Metformin group Glucose, cholesterol, TG, LDL levels significantly $(\mathrm{P}<0.05)$ decreased and HDL significantly $(\mathrm{P}<0.05)$ increased when compared to OLZ control group Table 2. It is reported that hypolipidemic effect of TF mediated by the ability of galactomannan to reduce absorption of lipids by inhibition of intestinal lipases enzyme and demonstrated anti-atherogenic effects via decreased serum LDL oxidation, increased biliary cholesterol excretions. ${ }^{46-47}$ SGOT and SGPT enzymes are a sensitive marker of liver damage and these enzymes levels are predictive of damage to the liver. Hence any necrosis or membrane damage to the liver leads to leakage of these enzymes into the blood circulation. In our findings significantly increase $(\mathrm{P}<0.05)$ of the level the diagnostic marker such as SGOT and SGPT respectively in OLZ group, when compared to normal control group. Effects of TF (SDF) on SGOT, SGPT, and uric acid were significantly reduced in the OLZ with TF 250 and 500 groups when compared to the OLZ group $(\mathrm{P}<0.05)$. OLZ+ Metformin treated group SGOT and SGPT decreased significantly $(\mathrm{P}<0.05)$ and uric acid reduced non-significantly in and when compare to OLZ treated rats. The reduced activities of the serum biomarker enzymes and enzymatic leakage in the liver may be due to enhanced antioxidant potential of TF seeds which could be responsible for attenuating reactive oxygen species induced oxidative stress and inflammation. ${ }^{48}$ It has been hypothesized that uric acid overproduction can trigger oxidative stress xanthine oxidoreductase (XO), the enzyme responsible for urate formation, may play a critical role in hyperuricemia and reduce the activity of nitric oxide synthase in metabolic syndrome. ${ }^{49}$ In studies of rats and humans, TF improved parameters associated with renal dysfunction due to the presence of antioxidant properties. ${ }^{50}$ Many investigations have confirmed the association of hyperuricemia with metabolic syndrome in antipsychotic patients. Uric acid may simply be a consequence of the increased uric acid absorption in the proximal tubule secondary to hyperinsulinemia there is growing data that uric acid may predict the development of metabolic syndrome, obesity, and diabetes. ${ }^{51}$ In our study in OLZ group, uric acid increased and TF $(250,500 \mathrm{mg} / \mathrm{kg})$ reduced compared with normal control rats. But metformin did not significantly reduce the uric acid level Table 2.

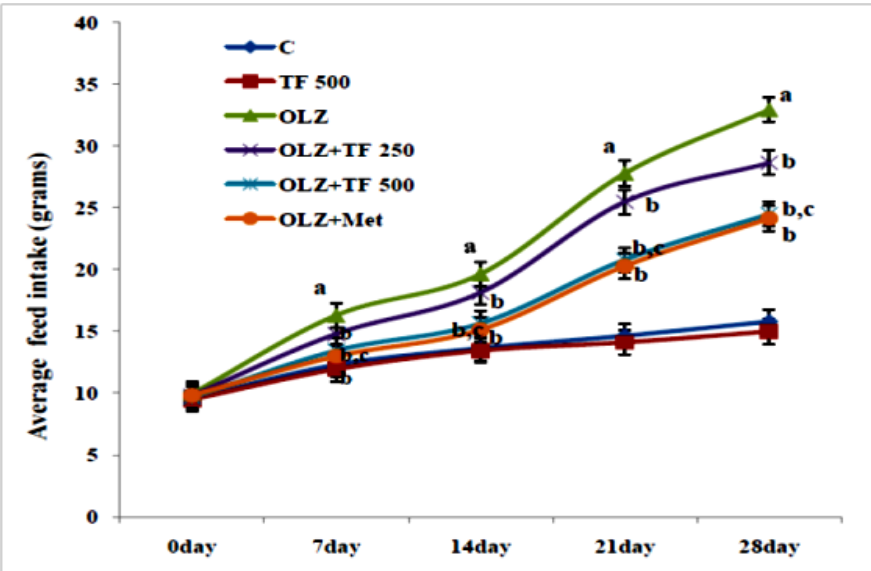

Figure 2 Effect of soluble dietary fiber fraction (SDF) of trigonella foenum graecum seeds (TF) on feed intake.

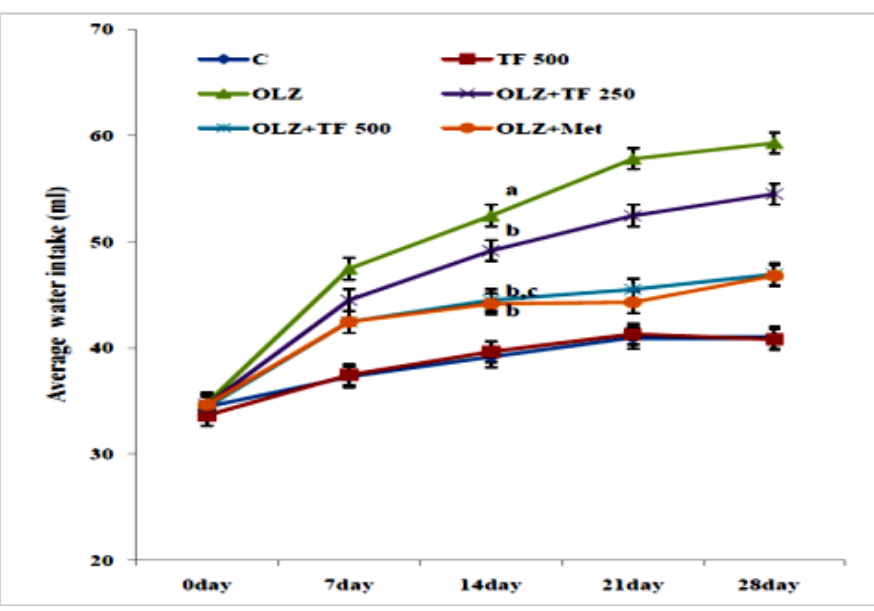

Figure 3 Effect of soluble dietary fiber fraction (SDF) of trigonella foenum graecum seeds (TF) on water intake.

\section{Effect of soluble diatery fraction (SDF) of trigonella foenum-graecum (TF) on oral glucose tolerace test (OGTT)}

Oral blood glucose concentrations were determined immediately after the rats fasted overnight. The OGTT results for olanzapine group rats at $0,30,60$ and $120 \mathrm{~min}$ after solution ingestion are significantly increased $(\mathrm{P}<0.05)$ as compared to control groups. Study groups OLZ+TF 250/500 and OLZ+ Metformin group glucose level significantly reduced when compared to OLZ group $(\mathrm{P}<0.05)$. OLZ $+\mathrm{TF}$ $(500 \mathrm{mg} / \mathrm{kg})$ showed significant decrease in glucose level at different time intervals compared to OLZ+TF $(250 \mathrm{mg} / \mathrm{kg}),(\mathrm{P}<0.05)$ Figure 4. Studies show that OLZ induced glucose and insulin dysregulation may be partly due to blockade of muscarinic $\mathrm{M}_{3}$ receptors, causing 
disruption to insulin secretion and glucose homeostasis that can progressively lead to insulin resistance and diabetes during chronic treatment. The ability to modify glucose homeostasis perhaps due to the presence of $\beta$-glucan and fiber fraction increased both insulinstimulation and basal glucose uptake by AMPK activation as reported in previous studies.

Table 2 Effect of soluble diateryfraction (SDF) of trigonella foenum-graecum (TF) on serum biochemical parameters

\begin{tabular}{|c|c|c|c|c|c|c|}
\hline Parameters & Normal Control & TF 500 & OLZ & OLZ+TF250 & OLZ+TF 500 & OLZ+METFORMIN \\
\hline Glucose (mg/dL) & $96.68 \pm 1.952$ & $93.53 \pm 2.788$ & $182.8 \pm 2.536^{\mathrm{a}}$ & $158.6 \pm 2.066^{b}$ & $120.4 \pm 0.733^{\mathrm{b}, \mathrm{c}}$ & $119.9 \pm 1.845^{b}$ \\
\hline Cholesterol (mg/dL) & $158.9 \pm 2.934$ & $158.00 \pm 3.448$ & $230.60 \pm 3.44^{8}$ & $214.10 \pm 2.335^{b}$ & $188.7 \pm 3.285^{b, c}$ & $183.45 \pm 1.198^{b}$ \\
\hline HDL (mg/dL) & $56.21 \pm 1.452$ & $57.73 \pm 0.666$ & $28.37 \pm 0.668^{\mathrm{a}}$ & $35.53 \pm 0.965^{b}$ & $44.87 \pm 1.01 I^{b, c}$ & $45.22 \pm 0.5167^{b}$ \\
\hline LDL (mg/dL) & $77.87 \pm 2.128$ & $74.47 \pm 3.401$ & $167.60 \pm 3.830^{\mathrm{a}}$ & $148.80 \pm 2.334^{b}$ & $117.15 \pm 3.337^{b, c}$ & $|09.6 \pm 0.757|^{b}$ \\
\hline TG (mg/dL) & $|24| \pm 2.422$. & $129.1 \pm 1.932$ & $160.2 \pm 1.782^{\mathrm{a}}$ & $\mid 48.7 \pm 1.034$ & $133.4 \pm 0.810^{b, c}$ & $129.4 \pm 0.952^{b}$ \\
\hline SGOT (IU/L) & $25.23 \pm 1.449$ & $23.98 \pm 1.495$ & $71.90 \pm 1.552^{\mathrm{a}}$ & $59.16 \pm 1.168^{b}$ & $36.77 \pm 0.9236^{b, c}$ & $44.23 \pm 0.8597^{b}$ \\
\hline SGPT (IU/L) & $33.13 \pm 1.203$ & $33.46 \pm 1.138$ & $81.09 \pm\left. 1.77\right|^{a}$ & $63.66 \pm 0.6415^{b}$ & $44.77 \pm 1.232^{\mathrm{b}, \mathrm{c}}$ & $54.32 \pm\left. 0.479\right|^{b}$ \\
\hline Uric Acid & $1.747 \pm 0.114$ & $1.573 \pm 0.147$ & $4.105 \pm 0.155^{\mathrm{a}}$ & $3.502 \pm 0.064^{b}$ & $2.767 \pm 0.1516^{\mathrm{b}, \mathrm{c}}$ & $3.772 \pm 0.17 \mid$ \\
\hline
\end{tabular}

The total duration of the study was 28 days.

Values are expressed as Mean $\pm \operatorname{SEM}(n=5-6) .{ }^{a}(p<0.05)$ vs normal control group;

${ }^{b}(p<0.05)$ vs olanzapine control group; ${ }^{c}(p<0.05)$ vs low dose TF $(250 \mathrm{mg} / \mathrm{kg})$ treatment group

(One way ANOVA followed by Tukey's test)

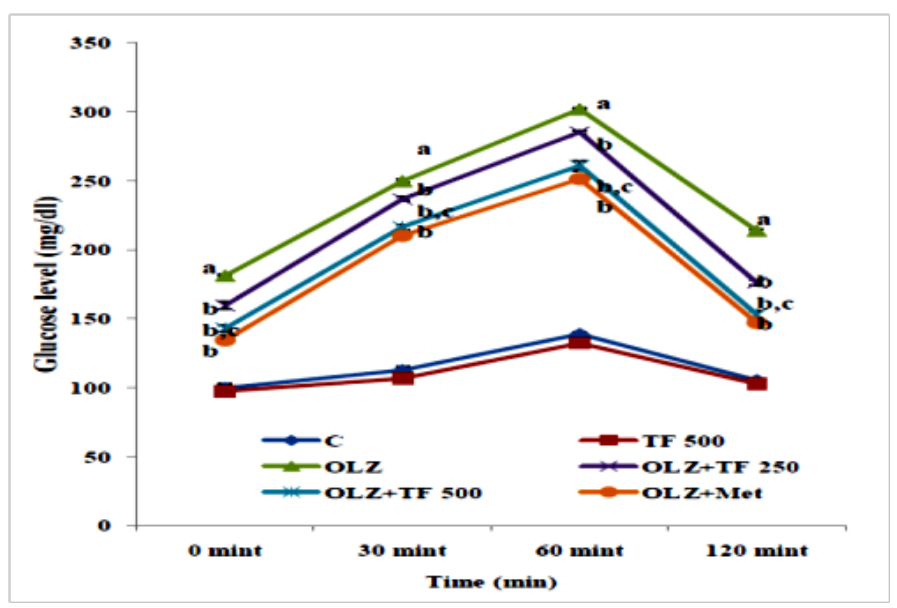

Figure 4 Effect of soluble diateryfraction (SDF) of trigonella foenum-graecum (TF) on Oral glucose tolerance test (OGTT).

\section{Effect of soluble diateryfraction (SDF) of trigonella} foenum-graecum (TF) on hemodynamic parameters

OLZ showed the significant reduction in the AP, MAP but elevation in the SAP, DAP, and HR in the heart was observed when compared to normal control group. Oral administration of metformin $(100 \mathrm{mg} / \mathrm{kg})$ show significant elevation $(\mathrm{P}<0.05)$ in the AP, MAP but a reduction in SAP, DAP, and HR in the heart when compared to olanzapine group. Treatment with TF $(250 \& 500 \mathrm{mg} / \mathrm{kg})$ shows significant elevation in the AP, MAP respectively $(\mathrm{P}<0.05)$, but the reduction in HR, SAP, and DAP with respect of dose when compared with olanzapine group.TF $(500 \mathrm{mg} / \mathrm{kg})$ showed more significantly results when compared to TF $(250 \mathrm{mg} / \mathrm{kg})(\mathrm{P}<0.05)$ Table 3. Further evidence for the cardioprotective effects of TF has emerged in cardiovascular disease including hypertension due to vasodilatory properties and also protects vascular function by increasing the expression of endothelial
NO synthase. ${ }^{52,53}$ Chronic treatment with olanzapine elevates systolic blood pressure in normal rats and weight gain is associated with elevation of diastolic blood pressure and it stimulates sympathetic nervous system activity which may elevate blood pressure. ${ }^{54}$ In the present study, administration of olanzapine shows a significant reduction in the AP, MAP but elevation in the SAP, DAP, and HR in the heart was observed when compared to normal control group. Oral administration of TF $(250 \& 500 \mathrm{mg} / \mathrm{kg})$ and metformin $(100 \mathrm{mg} /$ $\mathrm{kg}$ ) show a significant elevation in the AP, MAP but a reduction in SAP, DAP, and HR in the heart, when compared to OLZ group. The association between obesity and hypertension is well established in many studies. ${ }^{55}$ These observations are indicative of olanzapine induced weight gain playing a role in blood pressure elevation.

\section{Effect of soluble diateryfraction (SDF) of trigonella foenum-graecum (TF) cardiac TBARS and GSH}

The effect on TBARS and GSH of TF $(250$ and $500 \mathrm{mg} / \mathrm{kg}$ ) is depicted in Table 4 statistical analysis revealed that there was significant difference among the groups, It revealed that OLZ group showed significant $(\mathrm{P}<0.05)$ elevation in TBARS levels and reduction $(\mathrm{P}<0.05)$ in GSH levels compared to control. Study group OLZ+ Metformin and TF $(250$ and $500 \mathrm{mg} / \mathrm{kg})$ showed significant $(\mathrm{P}<0.05)$ decrease in TBARS and increase $(\mathrm{P}<0.05)$ GSH level compared to OLZ group. TF $(500 \mathrm{mg} / \mathrm{kg})$ showed significant $(\mathrm{P}<0.05)$ decrease in TBARS and increased $(\mathrm{P}<0.05)$ GSH levels compared to TF $(250 \mathrm{mg} / \mathrm{kg})(\mathrm{P}<0.05)$. Abnormalities in lipid metabolism decrease the strength of the ant oxidative defenses. Oxidative stress defined as a disruption of the delicate balance between oxidative and antioxidative process, play an important role in the pathogenesis of hypercholesterolemic atherogenesis. Oxygen free radicals (OFRs) are found to be produced during obesity and adiposity. ${ }^{56} \mathrm{GSH}$ has a direct antioxidant function by reacting with super oxide radicals and singlet oxygen followed by the formation of oxidized GSH. It plays an important role in the regulation of a variety of cell functions and in cell protection against oxidative injury. The antioxidant of TF may 
be due to its free radical scavenging activity which neutralizes the free radicals generated during oxidative stress. MDA is the stress marker that indicates lipidperoxidation of endogenous lipid has been shown to be a major risk factor in metabolic syndrome. Free radicals produced by endothelial injury could initiate peroxidation of membrane- bound polyunsaturated fatty acids, leading to myocardial injury. ${ }^{57}$ In the present investigation, administration of olanzapine increased the level of MDA when compared to normal control group. The correlation found between dyslipidemia and oxidative stress in this study shows that dyslipidemia induced by ingestion of OLZ is the primary cause of lipid peroxidation. Therefore, the possible reason for the improvement in dyslipidemia with TF may be due to the reduction in oxidative stress in OLZ treated rats by improving lipid peroxidation and antioxidant enzyme status. ${ }^{58}$

Table 3 Effect of soluble diateryfraction (SDF) of trigonella foenum-graecum (TF) on hemodynamic parameters

\begin{tabular}{|c|c|c|c|c|c|}
\hline Group & $\mathrm{AP}(\mathrm{mmHg})$ & HR(BPM) & MAP(mmHg) & SAP(mmHg) & $\mathrm{DAP}(\mathrm{mmHg})$ \\
\hline Normal & || $8.7 \pm 0.92 \mid$ & $362.9 \pm 1.722$ & $123 \pm 1.446$ & $120 \pm 1.253$ & $84.6 \pm 1.21$ \\
\hline Normal+TF (500mg/kg) & $119.7 \pm 0.710$ & $367.3 \pm 1.786$ & $120.8 \pm 1.482$ & $|2| .6 \pm 1.4 \mid 4$ & $84 . I \pm 0.78 I$ \\
\hline OLZ control $(5 \mathrm{mg} / \mathrm{kg})$ & $96.4 \pm 0.61 \mathrm{I}^{\mathrm{a}}$ & $419.4 \pm 1.983^{a}$ & $93.72 \pm 0.827^{a}$ & $|44.4 \pm| .429^{a}$ & $103.6 \pm\left. 1.24\right|^{a}$ \\
\hline OLZ+TF $(250 \mathrm{mg} / \mathrm{kg}$ & $104.3 \pm 0.725^{b}$ & $407.2 \pm 1.146^{b}$ & $101.9 \pm 1.116^{b}$ & $129.3 \pm 0.335^{b}$ & $97.8 \pm 0.427^{b}$ \\
\hline OLZ+TF (500mg/kg) & III. $8 \pm 0.943^{\mathrm{b}, \mathrm{c}}$ & $396.1 \pm 0.790^{\mathrm{b}, \mathrm{c}}$ & $112.7 \pm 1.107^{\mathrm{b}, \mathrm{c}}$ & $|24.| \pm 0.643^{b, c}$ & $92.6 \pm 0.427^{b, c}$ \\
\hline OLZ+Metformin (100mg/k) & $106.3 \pm 1.062^{\mathrm{b}}$ & $399.3 \pm 0.526^{b}$ & $108.6 \pm 0.778^{b}$ & $128.8 \pm 0.742^{\mathrm{b}}$ & $95.2 \pm 0.728^{b}$ \\
\hline
\end{tabular}

The total duration of the study was 28 days.

Values are expressed as Mean \pm SEM $(n=5-6) .{ }^{a}(p<0.05)$ vs normal control group; ${ }^{b}(p<0.05)$ vs olanzapine control group; ${ }^{c}(p<0.05)$ vs low dose TF $(250 \mathrm{mg} / \mathrm{kg})$ treatment group

(One way ANOVA followed by Tukey's test)

Table 4 Effect of soluble diateryfraction (SDF) of trigonella foenum-graecum (TF) cardiac lipid peroxidation (TBARS and GSH)

\begin{tabular}{lll}
\hline Group & MDA $(\mu \mathrm{mol} / \mathrm{ml})$ & GSH $(\mu \mathrm{mol} / \mathrm{ml})$ \\
\hline Normal & $50.7 \pm 1.225$ & $138.7 \pm 1.076$ \\
TF $(500 \mathrm{mg} / \mathrm{kg})$ & $49.71 \pm 0.853$ & $138.9 \pm 1.35 \mathrm{I}$ \\
OLZ control $(5 \mathrm{mg} / \mathrm{kg})$ & $82.26 \pm 1.022^{\mathrm{a}}$ & $55.66 \pm 1.72 \mathrm{I}^{\mathrm{a}}$ \\
OLZ+TF $(250 \mathrm{mg} / \mathrm{kg})$ & $67.46 \pm 0.80 \mathrm{I}^{\mathrm{b}}$ & $73.46 \pm 0.367^{\mathrm{b}}$ \\
OLZ+TF $(500 \mathrm{mg} / \mathrm{kg})$ & $54.6 \pm 1.154^{\mathrm{b}, \mathrm{c}}$ & $95.05 \pm 1.027^{\mathrm{b}, \mathrm{c}}$ \\
OLZ+Metformin $(100 \mathrm{mg} / \mathrm{kg})$ & $60.24 \pm 1.055^{\mathrm{b}}$ & $82.33 \pm 1.183^{\mathrm{b}}$ \\
\hline
\end{tabular}

The total duration of the study was 28 days.

Values are expressed as Mean \pm SEM $(n=5-6) .{ }^{a}(p<0.05)$ vs normal contro group; ${ }^{b}(p<0.05)$ vs olanzapine control group; ${ }^{c}(p<0.05)$ vs low dose TF $(250 \mathrm{mg} /$ $\mathrm{kg}$ ) treatment group

(One way ANOVA followed by Tukey's test)

Effect of soluble diatery fraction (SDF) of trigonella foenum-graecum (TF) on histopathological changes in liver

In addition to the previous hypothesis, olanzapine causes direct damage to the liver and oxidative stress that is reflected by derangement of hepatic cells using H\&E staining. ${ }^{59}$ The histopathological examination of the normal group showed normal cell architecture of the liver hepatocytes and no congestion of sinusoids. Hepatocytes were arranged in a network around the central vein while olanzapine group showed significant morphological changes such as degeneration, necrosis of hepatocytes in the liver cytoplasm and inflammation more, edema and congestion of blood vessels in the central vein. In metformin and SDF of TF, treated rats showed, considerably mild degenerations, less necrotic changes, congestion of blood vessels and edema and lesions were localized in some liver lobules in form of degenerative cell foci with fewer cells as compared to olanzapine treated rats Figure 5. Therefore, the present study suggests a protective effect of soluble dietary fiber rich fraction of Trigonella foenum-graecum on olanzapine induced metabolic syndrome in rats. Such antioxidant properties of the SDF fraction of TF seeds may be valuable in the prevention and possible reversal of metabolic complications. The increase in satiety may be due to the presence of galactomannan in the SDF fraction of TF and due to its viscous gel forming property, is effective in inhibiting the intestinal glucose uptake and suppress appetite in rats. Comparative study of Metformin also indicates that treatment with SDF rich fraction of TF improves the lipid profile, cardiac marker, antioxidant status, hemodynamic and histopathological alterations in olanzapine treated rats. The protective effect of TF may be related to its free radical scavenging and helpful in protection from the metabolic disorders. Overall, these results signify the importance of Trigonella foenum graceum, a novel source of dietary fiber in the management of antipsychotic induced metabolic complications.

In normal control (C) and TF control, showed the normal histological appearance of the liver hepatocytes and central vein. Hepatocytes were arranged in a network around the central vein. In OLZ group (arrows) showed, edema and necrosis of hepatocytes in the liver cytoplasm. OLZ+TF $(250 \mathrm{mg} / \mathrm{kg})$ showed less edema and necrotic changes. In OLZ+TF $(500 \mathrm{mg} / \mathrm{kg})$ and OLZ+ Metformin showed, considerably mild hepatic changes when compared to OLZ group and lesions were localized in some liver lobules in form of degenerative cell foci with fewer cells. 


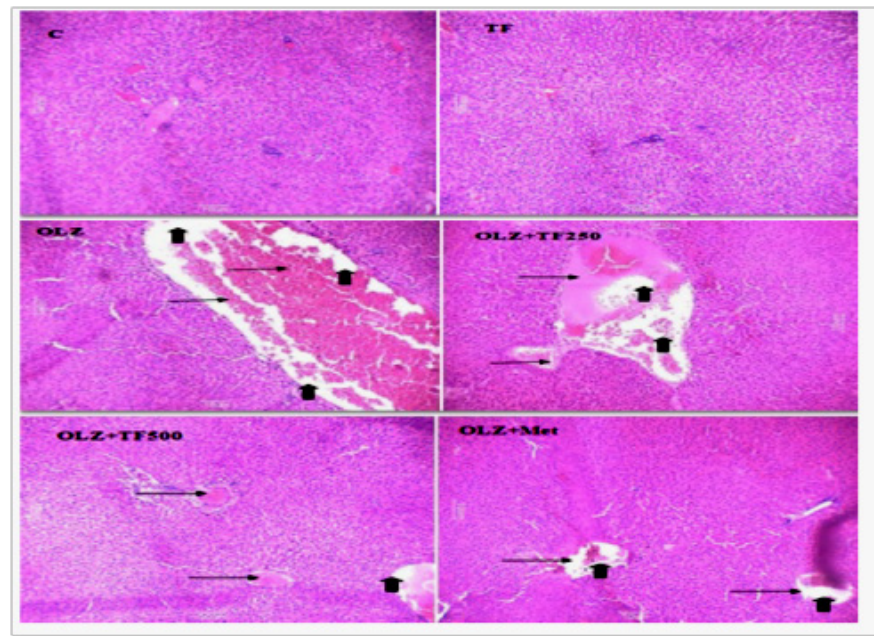

Figure 5 Effect of soluble diateryfraction (SDF) of trigonella foenum-graecum (TF) on hepatic histopathological changes in OLZ induced metabolic syndrome.

\section{Conclusion}

Based on the results of the present study it was concluded that soluble dietary fiber rich fraction of Trigonella foenum-graecum exert beneficially and of a promising role in olanzapine induced metabolic syndrome. These effects may have vital clinical importance and may be further improved, enhanced and should continue to be extensively studied.

\section{Acknowledgements}

Authors are thankful to the management committee of ASBASJS Memorial College of Pharmacy BELA (Ropar) for providing facilities to conduct the project.

\section{Conflict of interest}

Author declares that there is no conflict of interest.

\section{References}

1. Skrede S, Martins L, Berge RK, et al. Olanzapine depot formulation in rat: a step forward in modelling antipsychotic-induced metabolic adverse effects. International Journal of Neuropsychopharmacology. 2014;17(1):91-104.

2. Yogaratnam J, Biswas N, Vadivel R, et al. Metabolic complications of schizophrenia and antipsychotic medications-an updated review. East Asian archives of Psychiatry. 2013;23(1):21-28.

3. De Hert M, Detraux J, Van Winkel R, et al. Metabolic and cardiovascular adverse effects associated with antipsychotic drugs. Endocrinology. 2011;8(2):114-126.

4. Arjona AA, Zhang SX, Adamson B, et al. An animal model of antipsychotic-induced weight gain. Behavioural brain Research. 2004;152(1):121-127.

5. Holt RI, Peveler RC. Antipsychotic drugs and diabetes-an application of the Austin Bradford Hill criteria. Diabetologia. 2006;49(7):1467-1476.

6. Rojo LE, Gaspar PA, Silva H, et al. Metabolic syndrome and obesity among users of second generation antipsychotics: A global challenge for modern psychopharmacology. Pharmacological research. $2015 ; 101: 74-85$.
7. Davey KJ, Cotter PD, Sullivan O, et al. Antipsychotics and the gut microbiome: olanzapine-induced metabolic dysfunction is attenuated by antibiotic administration in the rat. Translational psychiatry. 2013;3:309-315.

8. Evers SS, Calcagnoli F, Van Dijk G, et al. Olanzapine causes hypothermia, inactivity, a deranged feeding pattern and weight gain in female Wistar rats. Pharmacology biochemistry behavior. 2010;97(1):163-169.

9. Lian J, Huang XF, Pai N, et al. Preventing olanzapine-induced weight gain using betahistine: a study in a rat model with chronic olanzapine treatment. Plos One. 2014;9(8):104160.

10. Atmaca M, Kuloglu M, Tezcan E, et al. Serum leptin and triglyceride levels in patients on treatment with atypical antipsychotics. The Journal of clinical psychiatry. 2003;64(5):598-604.

11. Milano W, Rosa M, Milano L, et al. Antipsychotic drugs opposite to metabolic risk: neurotransmitters, neurohormonal and pharmacogenetic mechanisms underlying with weight gain and metabolic syndrome. The open neurology journal. 2013;7:23-33.

12. Lieberman JA. Metabolic changes associated with antipsychotic use. Journal of clinical psychiatry. 2004;6(2):8-13.

13. Chang SC, Lu ML, Wang YC, et al. Combined therapy with thioridazine decreases plasma levels of quetiapine in Taiwanese schizophrenic patients. Therapeutic drug monitoring. 2012;34(3):345-348.

14. Delzenne NM, Cani PD. A place for dietary fibre in the management of the metabolic syndrome. Current opinion clinical nutrition and metabolic care. 2005;8(6):636-640.

15. Punna R, Giridharan NV. Hypolipidemic effect of soluble dietary fiber (galactomannan) isolated from fenugreek seeds in WNIN (GR-Ob) obese rats. J Med Plant Res. 2011;5(19):4804-4813.

16. Srinivasan K, Pradeep SR. Amelioration of oxidative stress by dietary fenugreek (Trigonella foenum-graecum L) seeds is potentiated by onion (Allium cepa) in streptozotocin-induced diabetic rats. Appl Physiol Nutr Metab. 2017;42(8):1-13.

17. Zameer S, Najmi AK, Vohora D, et al. A review on therapeutic potentials of Trigonella foenum graecum (fenugreek) and its chemical constituents in neurological disorders: Complementary roles to its hypolipidemic, hypoglycemic, and antioxidant potential. Nutr Neurosci. 2017;15:1-7.

18. Mandegary A, Pournamdari M, Sharififar F, et al. Alkaloid and flavonoid rich fractions of fenugreek seeds (Trigonella foenum-graecum L.) with antinociceptive and anti-inflammatory effects. Food Chem Toxicol. 2012;50(7):2503-2507.

19. Hannan JM, Rokeya B, Faruque O, et al. Effect of soluble dietary fibre fraction of Trigonella foenum graecum on glycemic, insulinemic, lipidemic and platelet aggregation status of Type 2 diabetic model rats. $J$ Ethnopharmacol. 2003;88(1):73-77.

20. Fuller S, Stephens JM. Diosgenin, 4-hydroxyisoleucine, and fiber from fenugreek: mechanisms of actions and potential effects on metabolic syndrome. Adv Nutr. 2015;6(2):189-197.

21. Mbarki S, Alimi H, Bouzenna H, et al. Phytochemical study and protective effect of Trigonella foenum graecum (Fenugreek seeds) against carbon tetrachloride-induced toxicity in liver and kidney of male rat. Biomed Pharmacother. 2017;88:19-26.

22. Bahmani M, Shirzad H, Mirhosseini M, et al. A Review on Ethnobotanical and Therapeutic Uses of Fenugreek (Trigonella foenum-graceum L). $J$ Evid Based Complementary Altern Med. 2016;21(1):53-62.

23. Basu TK, Srichamroen A, Thomson AB, et al. In vitro intestinal glucose uptake is inhibited by galactomannan from Canadian fenugreek seed (Trigonella foenum graecum L) in genetically lean and obese rats. Nutr Res. 2009;29(1):49-54. 
24. Roberts KT. The potential of fenugreek (Trigonella foenum-graecum) as a functional food and nutraceutical and its effects on glycemia and lipidemia. J Med Food. 2011;14(12):1485-1489.

25. Srichamroen A, Field CJ, Thomson AB, et al. The Modifying Effects of Galactomannan from Canadian-Grown Fenugreek (Trigonella foenumgraecum L) on the Glycemic and Lipidemic Status in Rats. J Clin Biochem Nutr. 2008;43(3):167-174.

26. Kumar P, Bhandari U. Common medicinal plants with antiobesity potential: A special emphasis on fenugreek. Anc Sci Life. 2015;35(1):58-63

27. Kenny O, Smyth TJ, Hewage CM, et al. Antioxidant properties and quantitative UPLC-MS analysis of phenolic compounds from extracts of fenugreek seeds and bitter melon (Momordica charantia) fruit. Food Chem. 2013;141(4):4295-4302.

28. Evans AJ, Hood RL, Oakenfull DG, et al. Relationship between structure and function of a dietary fibre: a comparative study of the effects of three galactomannans on cholesterol metabolism in the rats. Br J Nutr. 1992;68(1):217-229.

29. Vander Zwaal EM, Janhunen SK, Fleur SE, et al. Modelling olanzapine-induced weight gain in rats. Int $J$ Neuropsychopharmacol. 2014;17(1):169-186.

30. Ellman GL. Tissue sulphydryl groups. Arch Biochem Biophys 1959;82(1):70-77.

31. Ohkawa H, Onishi N, Yagi K. Assay for lipid peroxidation in animal tissue by thiobarbituric acid reaction. Anal Biochem. 1979;95(2):351-358.

32. Shah R, Subhan F, Ali G, et al. Olanzapine induced biochemical and histopathological changes after its chronic administration in rats. Saudi Pharm J. 2016;24(6):698-704.

33. Aguilar E, Coronas R, Caixàs A. Metabolic syndrome in patients with schizophrenia and antipsychotic treatment. Med Clin Barc. 2012;139(12):542-546.

34. Sentissi O, Epelbaum J, Olié JP, et al. Leptin and ghrelin levels in patients with schizophrenia during different antipsychotic treatment: a review. Schizophr Bull. 2008;34(6):1189-1199.

35. Albaugh V, Henry C, Bello N, et al. Hormonal and metabolic effects of olanzapine and clozapine related to body weight in rodents. Obesity. 2006;14(1):36-51.

36. $\mathrm{Hu}$ Y, Young AJ, Ehli EA, et al. Metformin and berberine preven olanzapine-induced weight gain in rats. PLoS One. 2014;9(3):93310.

37. Hendrick V, Dasher R, Gitlin M, et al. Minimizing weight gain for patients taking antipsychotic medications: The potential role for early use of metformin. Ann Clin Psychiatry. 2017;29(2):120-124.

38. Hamden K, Jaouadi B, Carreau S, et al. Inhibitory effect of fenugreek galactomannan on digestive enzymes related to diabetes, hyperlipidemia, and liver-kidney dysfunctions. Biotechnol Bioprocess Eng. 2010;15(3):407-413

39. Lazzari P, Serra V, Marcello S, et al. Metabolic side effects induced by olanzapine treatment are neutralized by $\mathrm{CB} 1$ receptor antagonis compounds co-administration in female rats. Eur Neuropsychopharmacol. 2017;27(7):667-678

40. Kim SF, Huang AS, Snowman AM, et al. Antipsychotic drug-induced weight gain mediated by histamine $\mathrm{H} 1$ receptor-linked activation of hypothalamic AMP-kinase. Proc Natl Acad Sci. 2007;104(9):3456-3459.

41. Razavi BM, Lookian F, Hosseinzadeh H. Protective effects of green tea on olanzapine-induced-metabolic syndrome in rats. Biomed Pharmacother. 2017;92:726-731.

42. Davoodi N, Kalinichev M, Korneev SA, et al. Hyperphagia and increased meal size are responsible for weight gain in rats treated sub-chronically with olanzapine. Psychopharmacology. 2009;203(4):693-702.

43. Weston-Green K, Huang X, Deng C. Second generation antipsychoticinduced type 2 diabetes: a role for the muscarinic M3 receptor. CNS Drugs. 2013;27(12):1069-1080.

44. Repin N, Kay BA, Cui SW, et al. Investigation of mechanisms involved in postprandial glycemia and insulinemia attenuation with dietary fibre consumption. Food Funct. 2017;8(6):2142-2154.

45. Murashita M, Inoue T, Kusumi I. Glucose and lipid metabolism of longterm risperidone monotherapy in patients with schizophrenia. Psychiatry Clin Neurosci. 2007;61(1):54-58.

46. Sharma MS, Choudhary PR. Hypolipidemic effect of fenugreek seeds and its comparison with atorvastatin on experimentally induced hyperlipidemia. J Coll Physicians Surg Pak. 2014;24(8):539-542.

47. Belguith-Hadriche O, Bouaziz M, Jamoussi K, et al. Comparative study on hypocholesterolemic and antioxidant activities of various extracts of fenugreek seeds. Food Chem. 2013;138(3):1448-1453.

48. Haeri MR, Izaddoost M, Ardekani MR, et al. The effect of fenugreek 4 hydroxyisoleucine on liver function biomarkers and glucose in diabetic and fructose-fed rats. Phytother Res. 2009;23(1):61-64.

49. Furukawa S, Takuya F, Michio S, et al. Increased oxidative stress in obesity and its impact on metabolic syndrome. J Clin Invest. 2004;114(12):1752-1761.

50. Zafar MI, Gao F. 4-Hydroxyisoleucine: A Potential New Treatment for Type 2 Diabetes Mellitus. Bio Drugs. 2016;30(4):255-262.

51. Soltani Z, Rasheed K, Kapusta DR, et al. Potential role of uric acid in metabolic syndrome, hypertension, kidney injury, and cardiovascular diseases: is it time for reappraisal? Curr Hypertens Rep. 2013;15(3):175-181.

52. Hamden K, Jaouadi B, Carreau S, et al. Inhibitory effect of fenugreek galactomannan on digestive enzymes related to diabetes, hyperlipidemia, and liver-kidney dysfunctions. Biotechnol Bioprocess Eng. 2010;15(3):407-413.

53. Manivannan J, Balamurugan E, Silambarasan T, et al. Diosgenin improves vascular function by increasing aortic eNOS expression, normalize dyslipidemia and ACE activity in chronic renal failure rats. Mol Cell Biochem. 2013;384(2):113-120.

54. Patil BM, Kulkarni NM, Unger BS. Elevation of systolic blood pressure in an animal model of olanzapine induced weight gain. Eur J Pharmacol. 2006;551(3):112-115.

55. Smith RC, Lindenmayer JP, Bark N, et al. Clozapine, risperidone, olanzapine, and conventional antipsychotic drug effects on glucose, lipids, and leptin in schizophrenic patients. Int J Neuropsychopharmacol. 2005;8(2):183-194.

56. Malhotra A, Kang BP, Cheung S, et al. Angiotensin II promotes glucose-induced activation of cardiac protein kinase $\mathrm{C}$ isozymes and phosphorylation of troponin I. Diabetes. 2001;50(8):1918-1926.

57. Harrison DG, Guzik TJ, Nosalski R, et al. Role of chemokine rantes in the regulation of perivascular inflammation, T-cell accumulation, and vascular dysfunction in hypertension. FASEBJ. 2016;30(5):1987-1999.

58. Sankar P, Subhashree S, Sudharani S. Effect of Trigonella foenumgraecum seed powder on the antioxidant levels of high fat diet and low dose streptozotocin induced type II diabetic rats. Eur Rev Med Pharmacol Sci. 2012;16(3):10-17.

59. Odaci E, Bilen H, Hacimuftuoglu A, et al. Long-term treatments with low-and high dose olanzapine change hepatocyte numbers in rats. A stereological and histopathological study. Arch Med Res. 2009;40(3):139-145 